The patient had previously developed several periods of hyponatraemia while taking diuretics. We have recently submitted a paper reporting a case of hyponatraemia due to the syndrome of inappropriate antidiuretic hormone secretion (SIADH) following commencement of therapy with citalopram in an elderly patient. Her only other medications were aspirin, folic acid, multivitamins and senna, none of which is known to be associated with hyponatraemia and SIADH.

A wide variety of psychotropic drugs have been implicated in causing SIADH, described in a large number of case reports (Spigset \& Hedenmalm, 1995) but systematic epidemiological and clinical studies are lacking. While some authors suggest hyponatraemia due to SIADH is an idiosyncratic effect of any antidepressant drug (Committee on Safety of Medicines, 1994), others postulate it is most likely a class effect of the SSRIs (Ball \& Herzberg, 1984), although a cross-over effect with TCAs has been reported (Bouman et al, 1997 , in press). None the less, the exact mechanism remains to be clarified.

Surprisingly, Voegeli \& Baumann (1996) state that age does not represent a risk factor for developing SSRI-induced hyponatraemia due to SIADH. We would disagree with this statement. Although the exact nature of agerelated changes in sensitivity to $\mathrm{ADH}$ remains an area of controversy, elderly people are particularly prone to developing hyponatraemia due to SIADH (Ball \& Herzberg, 1994; Committee on Safety of Medicines, 1994; Spigset \& Hedenmalm 1995; Bouman et al, 1997, in press). In the large majority of published case reports ( $>90 \%$ ) the age of the patient is over 65 years, particularly among those treated with SSRIs.

Ball, C. J. \& Herzbers, J. (1994) Hyponatraemia and selective serotonin inhibitors. International journal of Geriatric Psychiatry. 2. 819-822.

Bouman, K. P., Johnson, H., Thescoll-Serrana, C., et af (1997) Recurrent hyponatraemia associated with sertraline and lofepramine. Americon journal of Psychiotry, in press.

Committee on Safety of Modicines (1994) Antidepressantinduced hyponatraemia. Current Problems in Pharmocovigilance, 20, 5-6.

Splgset, O. \& Hedenmalm, K. (1995) Hyponatraemia and the syndrome of inappropriate antidiuretic hormone secretion (SIADH) induced by psychotropic drugs. Drug Sofety 12, 209-225

Voegell, J. \& Baumann, P. (199) Inappropriate secretion of antidiuretic hormone and SSRIs (letter). British journol of Psychiatry 162 524-525.

W. P. Bouman, H. Johnson, G Pinner Department of Health Care of the Elderly, University Hospital, Nottingham NG7 2UH

\section{Outcome of panic disorder}

Sir: The conclusion of O'Rourke et al (1996) in their follow-up study that panic disorder "is a stable clinical entity" is at variance with almost all other comparative studies, which show a wide variation in clinical diagnostic outcome ranging from complete recovery to alcohol dependence, major depression, social phobia, obsessive-compulsive disorder and agoraphobia. The authors defend their single assessment at five years only by the somewhat curious argument that their method avoids the "distorting research effects intrinsic to the prospective method". It is surely relevant that the authors found that an unspecified number of patients "experienced temporary episodes of depression and alcohol misuse" during the follow-up period but this does not enter into the analysis at five years. The choice of the ninth edition of the Present State Examination as a diagnostic bastion for evaluating panic disorder is also odd as this instrument has only one question concerned with panic in its 140 items and does not derive a CATEGO diagnosis of panic disorder. The sample of patients chosen in the study was also not typical of panic disorder as it was a particularly chronic group that had been ill for a mean of five years. As all patients were known to have panic disorder at the time of follow-up there could also have been some tendency for the original symptom pattern to be identified and replicated, particularly if Dr O'Rourke (the assessor) expected this at the outset of the study.

In our own work, diagnostic assessments by structured interview at onset and after 10, 16, 32, 52 and 104 weeks showed that of 66 patients with panic disorder at outset, $60(91 \%)$ had at least one diagnostic change over the next two years, $13(20 \%)$ to a depressive disorder only, $23(35 \%)$ to another anxiety disorder only, and 14 $(21 \%)$ to both. We should therefore like to suggest that the findings of O'Rourke et al make a useful contribution to the debate over the validity of individual diagnoses within the neurotic spectrum but should not be taken as typical of panic disorder as it exists in clinical practice. It would be interesting to know whether the same diagnostic stability in the Galway sample continues to be maintained over the longer time scale as, if the same findings are found with formal diagnostic schedules, the existence of special features such as the higher prevalence of anancastic personality features in Ireland (Kelleher, 1972; Scott et al, 1982) might contribute to such unusual stability.

Kelleher, M. \& (1972) Cross-national (Anglo-Irish) differences in obsessional symptoms and traits of personality. Psychological Medicine, 2, 33-41.

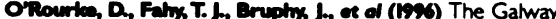
study of panic disorder. Ill: Outcome at 5 to 6 years. British Journal of Psychiotry 164, 462-469

Scout, A., Kelleher, M. b, Sinith, A., et of (ISex) Regional differences in obsessionality and obsessional neurosis. Psychological Medicine, 12, 131-134.

P. Tyrer Academic Unit of Psychiatry, St Charles Hospital, London WI0 6AZ

M. Seivewright Substance Misuse Service, 4 Norfolk Street, Sheffield SI 2JB

B. Fenguson Stonebridge Centre, Cardiff Street Carlton Road, Nottingham NG3 2FH

T. Johnson MRC Biostatistics Unit, University Forvie Site, Robinson Way, Cambridge CB2 2SR

Authors' reply: Tyrer et al wrongly assert that we concluded that panic disorder is a stable clinical entity. We said that the mirror image of Present State Examination (PSE) testretest after six years, although not conclusive, was difficult to reconcile with the notion that panic disorder is but one facet only of a general neurotic syndrome. That PSE does not define panic disorder with precision is very much to the point: PSE CATEGO-derived diagnoses are thereby less likely to be influenced by diagnostic bias. Their suggestion that our single rater cooked the PSE data is difficult to absolutely refute: if so, then the data were cooked to a turn to a correlation of 0.92 to be exact, a culinary achievement all the more remarkable since baseline PSE data were not available until after follow-up was complete.

Our sample of panic-disordered patients was not a "particularly chronic group": most reviewers, including Argyle \& Roth (1990), estimate mean chronicity at index as five to $\mathbf{1 0}$ years (five years in our sample). Tyrer et al ignore this notorious chronocity of panic disorder before treatment in their insistence on diagnostic musical chairs over time after treatment. They suggest that the reason why some results do not tally with theirs is that the former are biased by hospital practice. This time, however, the objection has no validity; our patients were treatment-naive, unpaid and were referred by general practitioners, as we have pointed out (Fahy et al, 1992; O'Rourke et al, 1996). If our patients were in any way special, it was in the notable absence of severe 